\title{
Bridging the Multiple Reality Gap: Application of Augmented Reality in New Product Development
}

\author{
Anna P. Chatzimichali ${ }^{1}$, Wim H. Gijselaers ${ }^{1}$, \\ Mien S.R. Segers ${ }^{1}$, Piet van den Bossche ${ }^{1}$, Hetty van Emmerik $^{2}$ \\ School of Business and Economics \\ ${ }^{1}$ Department of Educational Research and Development \\ ${ }^{2}$ Department of Organization and Strategy \\ Maastricht University \\ Maastricht, The Netherlands \\ a.chatzimichali@maastrichtuniversity.nl
}

\author{
Frido E. Smulders ${ }^{3}$, \\ Pieter P. Jonker ${ }^{4}$, Jouke C. Verlinden ${ }^{3}$ \\ ${ }^{3}$ Faculty of Industrial Design Engineering \\ ${ }^{4}$ Mechanical, Maritime and Materials Engineering \\ Delft University of Technology \\ Delft, The Netherlands
}

\begin{abstract}
Increased product complexity and internal team dynamics pose serious challenges to the quality of collaboration, usually reflected upon long delays, cost overruns and poor design quality during product development. Our focus is to study the factors that drive collaboration, shared understanding and team learning in product development in order to investigate new tools to facilitate this process. The present paper provides the theoretical framework to experiment with novel collaborative tools like Augmented Reality in the product development setting. The core argument is that Augmented Reality technologies act as a catalyst to the communication between the various stakeholders. The main idea behind this work is a dynamic investigation on the nature of collaboration in product development teams, through a socio-cognitive lens. The basic focus of this work is to connect insights from the social sciences to collaborative design and visualization technologies.
\end{abstract}

Index Terms-Collaborative design, Augmented Reality, New Product Development.

\section{INTRODUCTION}

The development of new products is an internally complex and dynamic process. The increased pressure of time-tomarket, the demand for high quality designs and the need for knowledge and expertise on new technologies pose serious challenges to product development teams. Shared understanding and communicating on the same vision usually does not come naturally to these interdisciplinary teams since each actor is holding a different view on the same issues. As a consequence, poor designs, costly delays and conflicts are many times the rule rather than the exception [1], [2].

Novel technologies, such as Augmented Reality, utilized as collaborative design tools can facilitate the sharing of expertise in teams and provide a key to overcome contextual differences [3], [4]. The use of such technologies enhances or augments the view of the real world with additional information and CAD representations of the product. However, the novelty of the present study rests on the fact that Augmented Reality is utilized not solely as a tool to enrich prototyping, but as a medium that increases the sensitivity of the team and facilitates communication, in order to bridge the barriers between the various stakeholders.
In this context, design is treated as a socio-cognitive process where knowledge and expertise are shared between the different stakeholders. Holding this point of view, the design process is considered as a learning process for all involved actors. They need to learn about the present state and the future possibilities of the product in order to conceptualize and envision not only the specifications, but also future shortcomings and obstacles during the development cycle.

In the field of design research it is not clear how such learning processes occur, nor how they can be enhanced to achieve higher effectiveness. However, research from the learning sciences in the field of education and team learning has consistently demonstrated that collaborative knowledge construction can be fostered by providing visualization tools as structural support [5]. Additionally, team learning literature uses a set of social and cognitive measure to improve the basis of communication and investigate the development of a shared mental model in teams [6].

This paper focuses on the strong connection between design and learning, two theories with different origins. Design theories, on one hand, focus more on the final product of design while, on the other hand, learning theories focus primarily on the process and not the product. Drawing the parallels between knowledge construction and team learning theory, we provide a theoretical background for product development. This framework intends to assess the quality of communication in "in vivo" case studies in aviation industry. Our main scope is to unveil a set of variables that contribute towards the understanding on how multi-professional design teams in aircraft design collaborate effectively.

The remainder of this paper is organized as follows. The next section presents a knowledge construction framework for product development. Section III presents a team learning framework, while Section IV draws the parallels between the two frameworks. Section $V$ gives the main points of the case study in VIP aircraft conversion service. Finally, the paper concludes with some observations in Section VI. 


\section{Knowledge Construction During Product DEVELOPMENT}

A fundamental source of complexity in multi-professional design teams is the need to synthesize the different perspectives of team members. Achieving shared understanding between groups of people that have different backgrounds and thus share fundamentally different views of the world is not simple. Additionally, the design of a new product requires not only the synthesis of existing, but also the development of new knowledge. This new knowledge should be constructed in a social and evolutionary process involving all stakeholders [7].

The following knowledge construction framework was initially developed to support software development processes [7]. Rooted in constructionism, an epistemological framework of building understanding and artifacts [8], knowledge construction can also describe successfully product design and development processes.

\section{A. The mechanism of knowledge construction}

Knowledge construction is defined as the co-evolution between artifacts and understanding [8] and according to [7] three basic processes.

1) Activation: The first step of knowledge construction is the activation of knowledge. Activation is the explication of knowledge and articulation of ideas in order to make them available to all stakeholders. The biggest challenge that product development teams face during this process is that knowledge is tacit and distributed across people, artifacts and organizations and, consequently, difficult and unpractical to be activated simultaneously from all these sources. An integrated prototype can facilitate in this process, providing a referential anchoring object where ideas can be pointed.

2) Communication: Communication is the transfer of ideas and knowledge from one team member to another and the creation of shared understanding among the shareholders. It requires a sense of common ground for the message to be both transmitted and received from both parties. The biggest challenge in the product development setting is the lack of common ground communication that comes from the diverse backgrounds of the team. An integrated prototype can facilitate communication, providing shared and explicit ground for understanding.

3) Envisioning: Finally, envisioning is the third process. To envision is to create understanding and visualize on the new possibilities and implications of the product. It is a process that extends towards the future and the basic challenge is to decide what ought to be done. The future product is a moving target and there is usually a high degree of uncertainty and ambiguity about the actual product requirements or the customers' needs. A prototype that can be experienced rather than imagined by all stakeholders can make the envisioning process easier.

\section{B. The creation of prototypes}

Prototypes usually help to overcome the basic challenges of knowledge construction. Their role is to stretch the relationship between the physical and the mental world by

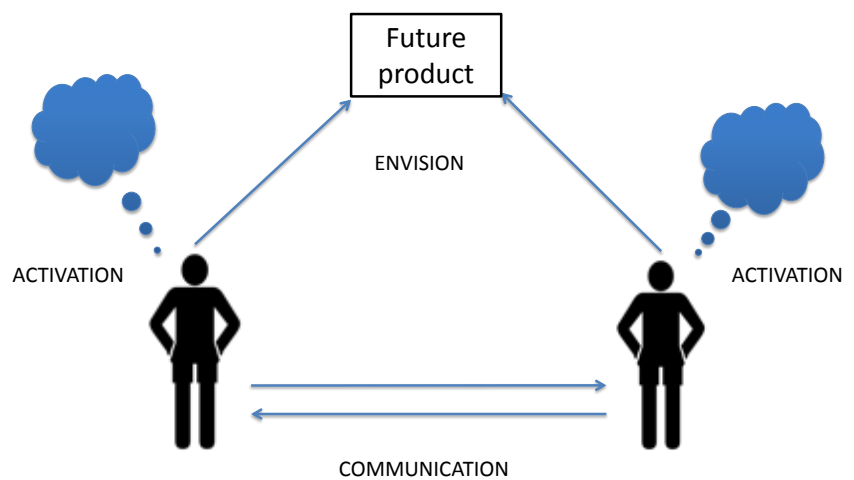

Fig. 1. The mechanism of knowledge construction

enabling shared understanding and providing foundation for new understanding. However, it is not always easy to create tangible prototypes, it requires valuable resources and multiple prototype versions according to the development phase.

The recent rise of Augmented Reality technology and its use in the product development setting could provide the base to address the challenges that teams face. Nevertheless, the introduction of a novel technology alone cannot make a team successful. Collaboration can flourish without any technology; however, technology can assist, support and enhance collaborative environments. To explore whether Augmented Reality is an appropriate tool for product development teams, we investigate further on the factors and parameters that create and enforce team learning in the next section.

\section{TEAM LEARNING FRAMEWORK}

Team learning is a fundamental process in product development. The present framework is based on an integrative model of team learning [6] and adapted for product development teams.

\section{A. The Social framework}

In this particular study we are going to focus on four specific factors that sketch the social framework of product development teams. Team diversity in terms of expertise level reflected upon members academic and previous experience background. Psychological safety that plays a critical role to the team's ability to develop innovative products in a timely manner [9]. And finally group potency and task cohesion, as a shared sense of identity, cohesiveness and purpose that motivates cooperative behavior, internal team dynamics and performance [10], [11], [12], [13].

\section{B. The Cognitive framework}

The above social frame is a base for the evolution of cognitive acts that drive sharedness and team learning. 


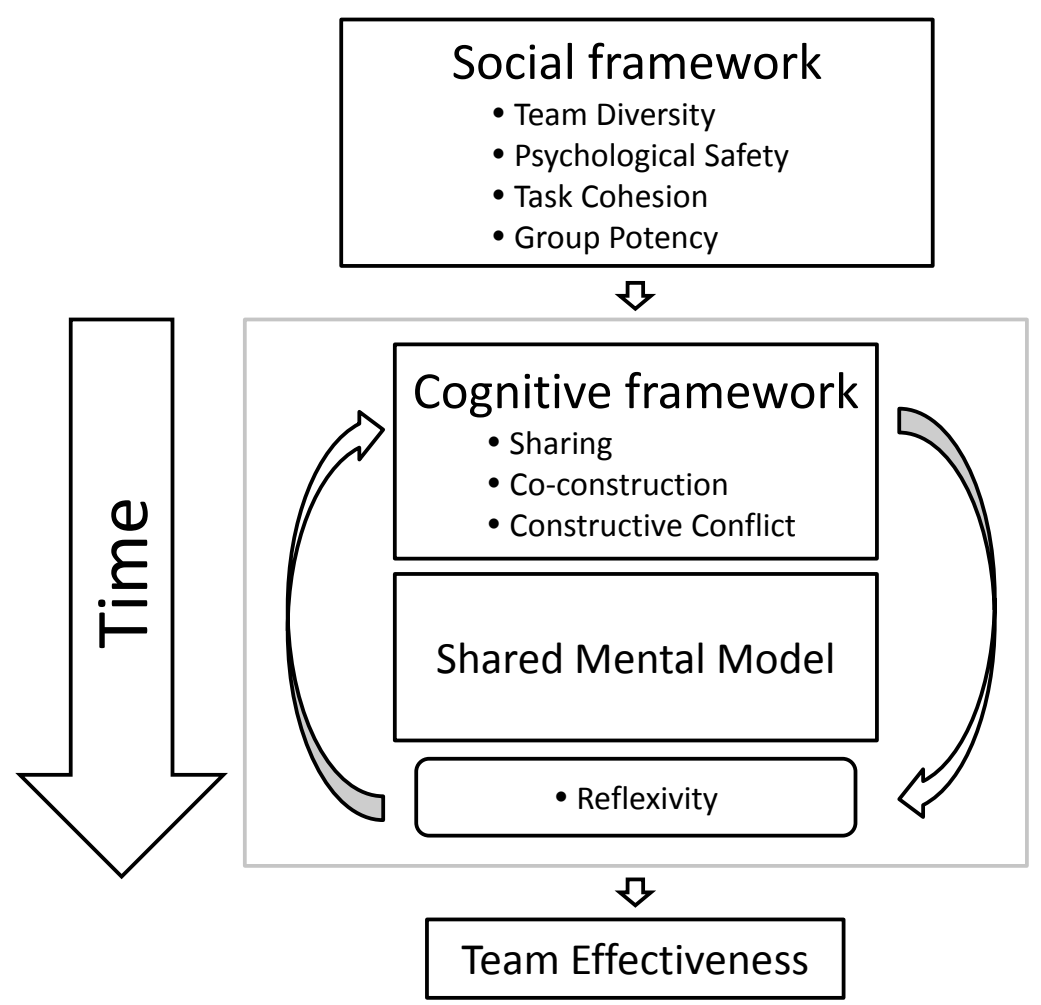

Fig. 2. A team learning socio-cognitive framework

1) Sharing: In this framework sharing is considered as the explication of knowledge, opinions or ideas between team members. Sharing is an important precondition for the other two interactions, co-construction and contractive conflict, to occur.

2) Co-construction: In co-construction team members take sharing one step further as they engage in repeated cycles of activities like acknowledging, repeating, paraphrasing, enunciating, questioning, concretizing and completing the shared knowledge, competencies, opinions or creative thoughts [6]

3) Constructive Conflict: The shared understanding that is developed through co-construction is not sufficient since it could only provide the common ground to build upon. It is the emergence of different opinions that makes "new" meaning emerge from the collaboration. This negotiation of meaning, rooted in the diversity of viewpoints, is what leads to better product designs.

\section{Team Mental Models}

A team mental model refers to an organized understanding or mental representation of knowledge that is shared among team members [14], [15]. A shared mental model starts to develop when agreement is reached around the co-constructed understandings [16].

The concept of team mental model is rather old in the literature, however, only recent research attempts to apply this concept in the design process [17], [18].

\section{Reflexivity}

Reflexivity is the feedback loop of learning. In this context is defined as the teams ability to co-construct, de-constuct and re-construct shared mental models, when through learning they reach their goals over and over again [6].

\section{E. Team Effectiveness}

In this case we approach team performance in terms of team/client satisfaction on the collaboration, product quality and time-to-market.

\section{TOWARDS An INTEgRATIVE APPROACH}

Despite the fact that both frameworks presented in the previous sections have their source in educational theory, they were adapted to fit the collaborative processes of product design and development. Additionally, if we take a closer look we can observe that the basic process of knowledge construction and cognition in team learning work in parallel (see table I).

Knowledge activation is parallel to Sharing since they both refer to making knowledge and ideas explicit. This is also the backbone of Communication that is running in parallel with Co-construction, expressed as exchange of ideas. Finally, Envisioning works in the same level with Constructive conflict, since they both are "breakdowns" [19] in the current reality that increase awareness, transform the team's understanding and drivers towards future goals. 
TABLE I

Addressing the Challenges through Augmented Reality Prototyping

\begin{tabular}{|c|c||c|c|}
\hline Constructivism & Team Learning & Challenges & AR / Prototyping \\
\hline \hline Activation & Sharing & Knowledge is implicit and distributed & Provide representations that can be reached to and pointed at \\
\hline Communication & Co-construction & Lack of common ground / language & Provide shared and explicit ground for understanding \\
\hline Envisioning & Constructive conflict & The future product is a moving target & Communicate ideas that can be experienced, rather than imagined \\
\hline
\end{tabular}

The case of this work, however, is to shed some light in how and why Augmented Reality can improve these fundamental functions. Augmented Reality can provide a link between sensory and abstract knowledge, connecting also the individual to the social world. This new tool can facilitate the elicitation of expert knowledge (Activation and Sharing), while it can also provide a common ground for the different perspectives of the stakeholders (Communication and Co-construction), (Envisioning and Constructive conflict). Additionally, the present framework is important for the development of this technology and for the further investigating of the reason why Augmented Reality tools can succeed or fail in various situations.

The same principles seem to underlie beyond the basic mechanism of learning and knowledge construction in team environments. This leaves room for further investigation towards a unifying theory of learning for design processes, yet putting theory into practice is the next vital step. In the following section we focus on a practical case study in VIP aircraft conversion. This real case will serve as a ground to test this framework and a valuable insight for the further development of team learning theories.

\section{THE CASE OF VIP AIRCRAFT CONVERSION INDUSTRY}

An ideal case to test our main hypothesis, that Augmented Reality can facilitate team learning and increase team effectiveness, is a case that integrates challenges of technical, aesthetic and social nature. The conversion of regular aircrafts to luxury private aircrafts is a process that involves various stakeholders, where each one has a different perspective on the same issues. In many cases, feedback about the actual product is possible during the final stage of production, only then many nonconformities become obvious. Additionally, the creation of prototypes (3D renderings and 1:1 scale models) is difficult and costly for aircraft interiors while leaving out many variables.

Beauty, status and comfort are dimensionless values and the customer is unable to get a clear idea of what he is actually buying based on renderings and floor plans. As a result, one of the biggest challenges in these projects is that the customer keeps changing his mind regarding the layout. On the other hand, the company prefers to freeze the layout fast in order to start engineering as soon as possible. Consequently, the engineering team needs to work on solutions without having previously defined the project accurately.

During the initial stages of development, Augmented Reality technologies can help bridge this communication gap between the client and the team providing a prototype that can be experienced by the client. Beside the customer interface,
Augmented Reality can also work as an interface between the multi-professional team members. This novel collaboration tool can assist the team to acquire realistic and integrated ideas as soon as possible. In other words, it can provide a token to the transition from design to prototype and from prototype to manufacturing.

This section investigates upon the social interactions that take place during this process in order to address methodology issues.

\section{A. Product Development Process}

The development of a new aircraft interior is a complicated process that involves multiple levels of interaction between the stakeholders. Here, we present a simplified version of reality in order to model the system effectively.

Figure 3 presents a flow chart of the processes that take place during the different phases of product development. The blue boxes represent collaboration and interactions between the main stakeholders. In the first stage the customer is independent from the team, while in the second stage he is integrated in the team taking part in the design review meetings. During the final stage the interaction shifts to design team and manufacturing team.

The input to the process are some initial requirements from the customer. Based on these requirements the team is preparing a first proposal that usually consist of elevation drawings and renderings. This is the sales phase and usually the proposal is refined until the client reaches his decision. These refinements are represented in the flow chart by the first feedback loop. If the client decides to purchase the conversion service, the next stage is the concept development, during which decisions on the details of the layout are made. The second feedback loop represents the modification on the requirement made on this phase. During this stage the client and the product development team usually communicate through a sales representative, however, during the next stage the client becomes a "member" of the team. Once the contract has been signed the whole layout needs to freeze and further changes add extra cost.

The next stage is the detailed design phase. The client participates in the course of the design review meetings and follows each step of the design process. Once the final technical specification have been decided the engineering team starts collaboration with manufacturing.

At this point we can observe three feedback loops. The continuous line feedback is the typical manufacturability refinement that takes place at this stage, where some technical 


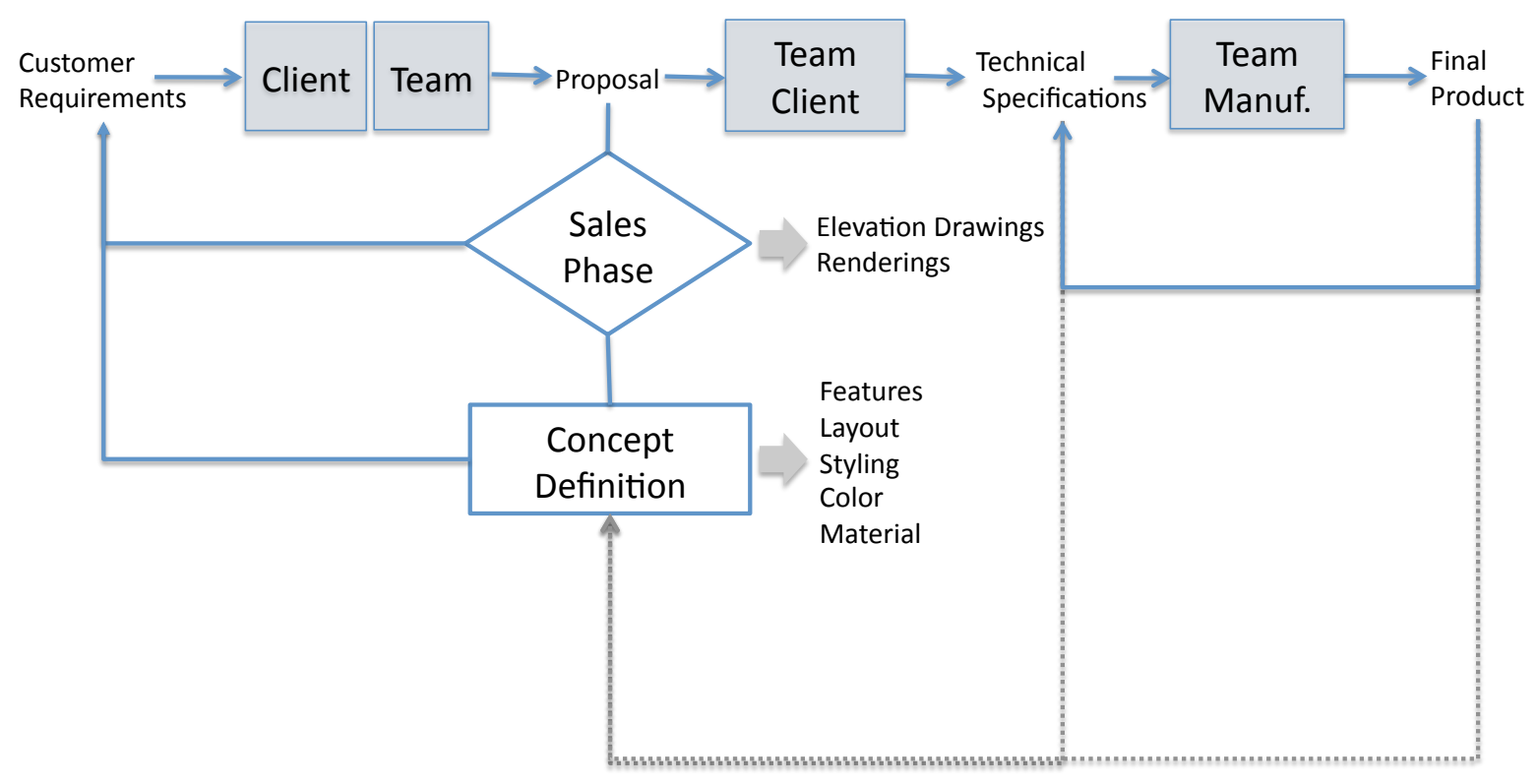

Fig. 3. Product development in VIP Aircraft conversion

specification are modified for reasons related to manufacturing and construction. The two other dotted line loops however, represent changes in the concept that are related either to the miscommunication between team members, or to changes related to the customers' wishes. The focus of Augmented Reality is in facilitating the continuous line loops and eliminating the dotted line loops by aiding the customer to make confident design decisions and the team to collaborate more effectively.

\section{B. Methodology}

Team learning varies according to the different stages of the product development process, the different environmental conditions and innovation types [20], [1]. Despite this evolution in learning strategies through time and phase of development, the literature approaches these phenomena rather statically. Little is known about team mental model development and change over time and regarding their impact on the design process [21]. This study focus specifically on the behavior of measurements over time and product development stage.

Mental models can be described as simple representations of the world and describe the way knowledge is structured. The measurement of team mental models should reveal the degree of convergence among team members with regard to content between known elements, as well as structure between these elements [22]. In this particular study team mental models are going to be indicated by self-reports and observation of external communication in the various phases of product development.
The main focus is to capture the basic ingredients that make collaboration effective between team members. The team learning framework is going to be utilized as a base to model the content of a series of design review meetings and a tool for an in depth analysis. In parallel with self reports and questionnaires we are also going to develop a coding scheme for transcript coding of the review meetings oriented mainly on the evolution of shared understanding. A comparative study between teams that use Augmented Reality and teams that do not, is going to reveal the core advantages of this collaboration tool and valuable insights on the nature of collaboration in product development teams.

\section{CONCLUSION}

Previous research on the airspace design field demonstrates that the influence of the artifact used in the design meetings plays an important role in the structure of the information process [23] and thus to the effectiveness of the team. This study serves as a basis for the further development of Augmented Reality technologies as a prototyping tool. This first step focuses on the clarification of the important factors, providing the basic framework in the experimentation with Augmented Reality technologies in aviation industry. The next step is to collect a set of meaningful data and analyze the communication dynamics during design discourses.

The main scope of this work was to uncover and describe the socio-cognitive parameters of collaboration in product development teams in order to investigate how Augmented Reality technologies can facilitate the process. The development 
of new products is a highly complex function that involves multiple learning processes [24]. However, team learning behavior as a dynamic social expression of human intellect is not easily measured. Hence, in this study we turned to research from the field of learning sciences to model the delicate dynamics of collaboration during product development.

\section{ACKNOWLEDGMENT}

The authors would like to thank Fokker Services and Driessen Airospace for their collaboration.

The project is supported by a grant from the Network for Social Innovation.

\section{REFERENCES}

[1] A. C. Edmondson and I. M. Nembhard, "Product Development and Learning in Project Teams: The Challenges Are the Benefits," Journal of Product Innovation Management, vol. 26, no. 2, pp. 123-138, 2009.

[2] B. A. Bechky, "Sharing Meaning Across Occupational Communities : The Transformation of Understanding on a Production Floor," Organization Science, vol. 14, no. 3, pp. 312-330, 2003.

[3] J. Verlinden and I. Horváth, "Analyzing opportunities for using interactive augmented prototyping in design practice," AI Edam Artificial Intelligence For Engineering Design Analysis And Manufacturing, vol. 23, no. 03, pp. 289-303, 2009.

[4] J. Verlinden, I. Horváth, and T.-J. Nam, "Recording augmented reality experiences to capture design reviews," International Journal on Interactive Design and Manufacturing IJIDeM, vol. 3, no. 3, pp. 189-200, 2009.

[5] F. Fischer, J. Bruhn, C. Grasel, and H. Mandl, "Fostering collaborative knowledge construction with visualization tools," Learning and Instruction, vol. 12, no. 2, pp. 213-232, 2002.

[6] S. Decuyper, F. Dochy, and P. Van Den Bossche, "Grasping the dynamic complexity of team learning: An integrative model for effective team learning in organisations," Educational Research Review, vol. 5, no. 2, pp. 111-133, 2010

[7] J. Ostwald, "Knowledge Construction in Software Development: The Evolving Artifact Approach," Ph.D. dissertation, Univ. of Colorado, 1996. [Online]. Available: www.cs.colorado.edu/ ostwald/thesis

[8] S. Paper, The children's machine. New York: Basic Books, 1993.

[9] A. C. Edmondson, "Psychological Safety and Learning Behavior in Work Teams," Administrative Science Quarterly, vol. 44, no. 2, p. 350, 1999.

[10] K. Bettenhausen, "Five Years of Groups Research: What We Have Learned and What Needs to Be Addressed," Journal of Management, vol. 17 , no. 2 , pp. $345-381,1991$.

[11] N. Ellemers, R. Spears, and B. Doosje, "Sticking Together or Falling Apart:In-Group Identification as a Psychological Determinant of Group Commitment versus Individual Mobility." Journal of Personality and Social Psychology, vol. 72, no. 3, pp. 617-626, 1997.

[12] P. J. Hinds and M. Mortensen, "Understanding Conflict in Geographically Distributed Teams: The Moderating Effects of Shared Identity, Shared Context, and Spontaneous Communication." Organization Science, vol. 16, no. 3, pp. 290-307, 2005.

[13] T. Tyler and S. Blader, "Identity and Cooperative Behavior in Groups." Group Processes and Intergroup Relations, vol. 4, no. 3, pp. 207-226, 2001.

[14] J. A. Cannon-Bowers, E. Salas, and S. Converse, Shared mental models in expert team decision making. In N.J. Castellan, Jr (Ed.), Individual and group decision making. Hillsdale, NJ: Erlbaum, 1993.

[15] R. Klimoski and S. Mohammed, "Team mental model: Construct or metaphor?" Journal of Management, vol. 20, pp. 403-37, 1994.

[16] P. Van den Bossche, "Social and Cognitive Factors Driving Teamwork in Collaborative Learning Environments: Team Learning Beliefs and Behaviors," Small Group Research, vol. 37, no. 5, pp. 490-521, 2006.

[17] F. Smulders, L. Lousberg, and K. Dorst, "Towards different communication in collaborative design," International Journal of Managing Projects in Business, vol. 1, no. 3, pp. 352-367, 2008.

[18] P. Badke-Schaub, A. Neumann, K. Lauche, and S. Mohammed, "Mental models in design teams: a valid approach to performance in design collaboration?" CoDesign, vol. 3, no. 1, pp. 5-20, 2007.
[19] P. Ehn, Work-Oriented Design of Computer Artifacts. Stockholm, Sweden: Almquist \& Wiksell International, 1988.

[20] A. E. Akgun, G. S. Lynn, and R. Reilly, "Multi-dimensionality of Learning in New Product Development Teams." European Journal of Innovation Management, vol. 5, no. 2, pp. 57-72, 2002.

[21] P. Badke-Schaub, K. Lauche, A. Neumann, and A. Saeema, Task, Team, Process: The Development of Shared Representation in an Engineering Design Team. CRC Press / Balkema, Taylor \& Francis Group, 2009, ch. 9 , pp. $153-170$.

[22] S. Mohammed, R. Klimoski, and J. R. Rentsch, "The Measurement of Team Mental Models: We Have No Shared Schema," Organizational Research Methods, vol. 3, no. 2, pp. 123-165, 2000.

[23] G. Huet, S. J. Culley, C. A. McMahon, and C. Fortin, "Making sense of engineering design review activities," Ai Edam, vol. 21, no. 03, pp. 243-266, 2007.

[24] A. P. Chatzimichali and V. D. Tourassis, "System dynamics and learning: Learning during the product realization chain," Systems Man and Cybernetics (SMC), 2010 IEEE International Conference on, pp. 2506 - 2511, 2010. 